\title{
Repetitive single subarachnoid injections for trial admini- stration of the intrathecal morphine pump in patients with intractable non-cancer pain
}

\section{-A case report-}

\author{
Jae-Woo Lee ${ }^{1}$, Kyung Ream Han², Seung-Ho Kim³ , Ji-Young Lee ${ }^{2}$, Do-Wan Kim², and Chan Kim² \\ Department of Anesthesiology and Pain Medicine, ${ }^{1}$ Eulji Hospital, College of Medicine, Eulji University, Seoul, ${ }^{2}$ Ajou University \\ Hospital, College of Medicine, Ajou University, Suwon, ${ }^{3}$ College of Medicine, Konyang University, Daejeon, Korea
}

Since the early 1980s, the implantable intrathecal drug pump (ITDP) has been used increasingly to manage chronic pain. Prior to making a decision to implant an ITDP, trial administration of the intrathecal (IT) drug should be performed to estimate the effective dose for a starting set of implantable ITDPs. There is no standard method of trial IT drug administration, though. Therefore, this paper reports 20 cases of IT morphine trial with single and repetitive injections until the appropriate dose was attained with respect to analgesia and its side effects. The trial procedure was performed with daily sequential IT injections using morphine and $0.3 \%$ mepivacaine. Twelve out of the total of 20 patients had positive responses. Thus, it is inferred that daily sequential IT morphine injections combined with a placebo injection as a trial ITDP would be useful in evaluating the effectiveness and adverse effects of IT morphine infusion with clinically insignificant side effects. (Korean J Anesthesiol 2011; 60: 138-141)

Key Words: Intractable pain, Intrathecal, Morphine, Pump.

The prevalence of moderate to severe chronic non-cancer pain in the general population has been reported to be $9-19 \%$ [1]. The most common condition of intractable chronic pain is neuropathic in nature, including complex regional pain syndrome (CRPS), post-laminectomy pain syndrome (PLPS, which is persistent pain following back surgery), and pain caused by nervous system injury or dysfunction. Treatments for chronic pain should employ a multidisciplinary approach. Although all modalities for the management of chronic pain have been tried, some chronic pain patients are still suffering from intractable pain. Currently, neuromodulation therapies such as stimulation of the spinal cord, thalamus, or motor cortex, and intrathecal (IT) drug infusion could be final options to managing intractable chronic pain $[2,3]$.

Received: September 16, 2010. Revised: October 11, 2010. Accepted: November 2, 2010.

Corresponding author: Kyung Ream Han, M.D., Ph.D., Department of Anesthesiology and Pain Medicine, Ajou University Hospital, San 5 Woncheon-dong, Paldal-gu, Suwon 442-721, Korea. Tel: 82-31-219-5689, Fax: 82-31-219-5579, E-mail: painhan@hanmir.com

(c) This is an open-access article distributed under the terms of the Creative Commons Attribution Non-Commercial License (http:// creativecommons.org/licenses/by-nc/3.0/), which permits unrestricted non-commercial use, distribution, and reproduction in any medium, provided the original work is properly cited. 
For modern pain medicine, opioid receptors in the nervous tissues were first found in 1973 [4]. The first clinical use of IT morphine to treat intractable cancer pain was reported by Wang et al. in 1979 [5]. In addition to that, continuous IT drug infusion using an implantable pump was introduced in a chronic cancer pain patient in 1981 [6]. Since the early 1980s, the implantable IT pump has been used increasingly to manage chronic pain, as the technology for the device has also been developed.

IT analgesia could have benefits for patients with intractable pain after they have undergone all the treatment modalities of or taken a high dose of opioid therapy. Successful use of IT implantable devices should be preceded, however, by the determination of the appropriate analgesic dosefor. Clinical practitioners have used different methods for this, such as intrathecal or epidural bolus injection, and intrathecal or epidural indwelling catheter placement. So far, however, there is still no standard method of trial IT drug administration. Therefore, this paper reports 20 cases of IT morphine trial with single and repetitive injections until the appropriate dose was attained with respect to analgesia and its side effects.

\section{Case Report}

A total of 20 patients with intractable chronic pain who had trial intrathecal morphine injections between March and August 2009 at the pain clinic of the authors' university hospital were included in this study. All of them had severe chronic pain with non-malignant refractory to conservative management, such as oral or parenteral opioids and multiple therapies.

The participants' informed consent was obtained after the nature of this study was explained to them. Then they were placed in a lateral decubitus position on a table, and their skin was prepared for needle insertion using an iodine-based antiseptic solution. A 25-gauge $10 \mathrm{~cm}$ spinal needle (Hakko ${ }^{\circledR}$, Hakko, Japan) was inserted in the L3-4 or L4-5 interspinous space and advanced to obtain a spontaneous flow of cerebrospinal fluid (CSF).

After confirming the CSF free flow through a needle, a mixed solution of morphine sulfate $(1 \mathrm{mg} / \mathrm{ml} /$ ampule: BCWorld Pharmacy Co., Ltd., Seoul, Korea) and 0.3\% mepivacaine $\left(\right.$ Mevan $^{\circledR}, 20 \mathrm{mg} / \mathrm{ml} /$ vial: HANLIM, Korea) was administered intrathecally. These two drugs do not contain preservatives. The morphine dose was measured with a $1 \mathrm{ml}$ syringe and mixed with $2 \mathrm{ml}$ of $0.3 \%$ mepivacaine in a $5 \mathrm{ml}$ syringe. Only in the case of the use of $0.075 \mathrm{mg}$ of morphine was morphine diluted first with $0.3 \%$ mepivacaine. For example, $1 \mathrm{ml}(1 \mathrm{mg})$ of morphine and $1 \mathrm{ml}$ of $0.3 \%$ mepivacaine were mixed in a 5 $\mathrm{ml}$ syringe, and then $0.15 \mathrm{ml}(0.075 \mathrm{mg})$ of the mixed solution was withdrawn to formulate the injection solution with 2 $\mathrm{ml}$ of $0.3 \%$ mepivacaine. The total volumes of the injection solution were $2.15 \mathrm{ml}$ (morphine, $0.075 \mathrm{mg}$ and $0.15 \mathrm{mg}$ ), 2.3 $\mathrm{ml}$ (morphine, $0.3 \mathrm{mg}$ ), $2.5 \mathrm{ml}$ (morphine, $0.5 \mathrm{mg}$ ), and $2.7 \mathrm{ml}$ (morphine, $0.7 \mathrm{mg}$ ), depending on the morphine doses. The morphine dose was determined based on the amount of oral opioids and the patient's age. If the patient was below 65 years old or consumed opioids with an equivalent dose of more than $90 \mathrm{mg}$ of morphine, $0.3 \mathrm{mg}$ of morphine was used for the initial dose. If the patient was more than 65 years old or consumed opioids with an equivalent dose of less than $90 \mathrm{mg}$ of morphine, $0.15 \mathrm{mg}$ of morphine was administered for the initial dose. If the patient had a poor clinical condition, the first trial injection was made with $0.075 \mathrm{mg}$ of morphine. A positive response was

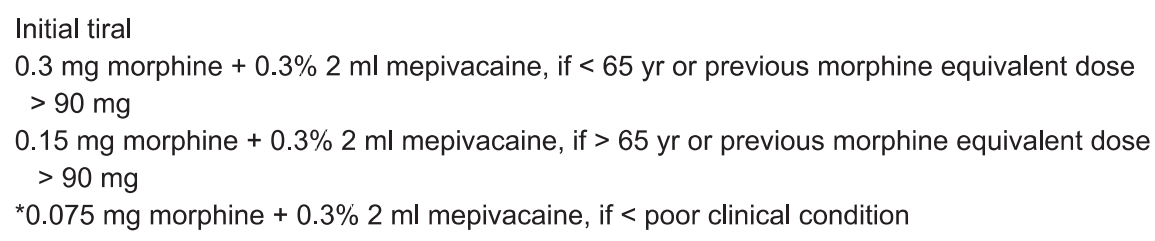

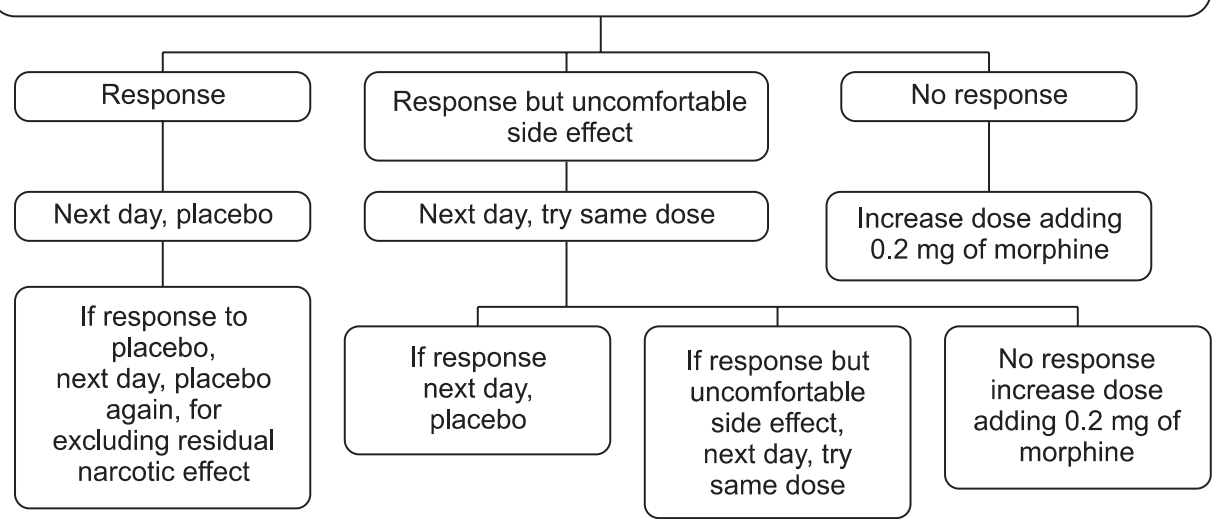

Fig. 1. The study protocol. $0.075 \mathrm{mg}$ $(0.075 \mathrm{ml})$ of morphine was mixed with $0.075 \mathrm{ml}$ of $0.3 \%$ mepivacaine first, and $2.15 \mathrm{ml}$ of mixed solution containing of $0.075 \mathrm{mg}$ of morphine with 2.075 $\mathrm{ml}$ of $0.3 \%$ mepivacaine was used for intrathecal test dose. 
defined as at least $50 \%$ pain relief in 8 hours after the intrathecal administration of the trial morphine. The study protocol is summarized in Fig. 1.

If the patient had a positive response but an uncomfortable side effect, the first dose of morphine was used for the second trial injection to evaluate the possibility of the degradation of the side effect. If a patient had a negative response with 0.075 or $0.15 \mathrm{mg}$ of initial morphine, a double dose of initial morphine was administered to see if the positive response would be induced. If a patient had a negative response with $0.3 \mathrm{mg}$ of morphine, $0.2 \mathrm{mg}$ of morphine was added to the previous injection on the next day. If a patient had a positive response to the trial intrathecal injection at any dose of morphine, $2 \mathrm{ml}$ of normal saline was administered intrathecally to rule out the

Table 1. Demographic Data of the Study Patients

\begin{tabular}{lc}
\hline Number & 20 \\
Age (range) & $44.1(16-78)$ \\
Sex (male/female) & $14 / 6$ \\
Diagnosis & \\
$\quad$ Postlaminectomy syndrome - lumabar & 5 \\
Postlaminectomy syndrome - cervical & 3 \\
CRPS & 4 \\
PHN & 1 \\
Central pain & 3 \\
Others & 4
\end{tabular}

PLPS-L: Post-laminectomy syndrome - lumabar, PLPS-C: Postlaminectomy syndrome - cervical, CRPS: complex regional pain syndrome, PHN: postherpetic neurallgia. placebo effect on the next day.

The pain relief and side effects were evaluated with a numerical rating scale (NRS) of 0 to 10 (where 0 means nothing and 10 represents the worst condition imaginable) at each injection.

A total of 20 patients underwent trial IT morphine injections. Fourteen patients were male and six were female. The patients' clinical characteristics and the results of this study are summarized in Table 1 and 2, respectively. The mean age of the study patients was $44(16-78)$ years. The average number of trial injections was 3 .

Twelve (60\%) of the total number of patients had a positive response. The average pain relief was described with NRS 2.8 from 8 of the subjects. Six of the subjects underwent implantation of an intrathecal drug pump (ITDP). One of the 12 subjects, a 61-year-old man with post-laminectomy pain syndrome (PLPS), did not receive an implantation of ITDP because of the morphine-induced side effect of urinary retention. The high cost of ITDP implantation was cited most often as the reason for rejecting the performance of the procedure.

Three (15\%) of the patients did not experience side effects. Seventeen patients experienced side effects, the most common of which were itching $(11 / 20)$, urinary retention $(9 / 20)$, nausea $(4 / 20)$, dizziness $(2 / 20)$, and postdural puncture headache (PDPH) (1/20). Twelve of 17 patients with side effects reported mild degrees of degradation with repetitive injections. Five of the eight non-responders experienced moderate to severe degrees of side effects.

Table 2. Summary of Patient Characteristics and Outcome of Intrathecal Morphine Infusion as a Diagnostic Test

\begin{tabular}{|c|c|c|c|c|c|c|c|c|c|}
\hline No. & Diagnosis & Pre NRS & Post NRS & $\mathrm{S}(\mathrm{mg})$ & $\mathrm{F}(\mathrm{mg})$ & $\begin{array}{c}\text { Number } \\
\text { of test }\end{array}$ & S/Ex & $\begin{array}{c}\text { Pump } \\
\text { implatation }\end{array}$ & $\begin{array}{c}\text { Cause of } \\
\text { refusal }\end{array}$ \\
\hline 1 & Central pain & 9 & 9 & 0.3 & 0.3 & 3 & DU, I, N & $\mathrm{n}$ & $\mathrm{NE}$ \\
\hline 2 & Central pain & 5 & 2 & 0.3 & 0.5 & 6 & I & $\mathrm{n}$ & Other \\
\hline 3 & Central pain & 10 & 0 & 0.15 & 0.3 & 3 & $\mathrm{D}$ & $\mathrm{y}$ & . \\
\hline 4 & CRPS & 9 & 4 & 0.3 & 0.3 & 1 & DU, I & $\mathrm{n}$ & Change to SCS \\
\hline 5 & CRPS & 8 & 4 & 0.3 & 0.3 & 3 & I & $\mathrm{y}$ & . \\
\hline 6 & CRPS & 7 & 3 & 0.3 & 0.5 & 8 & DU, I & $\mathrm{y}$ & . \\
\hline 7 & CRPS & 6 & 6 & 0.15 & 0.3 & 2 & DU, I & $\mathrm{n}$ & $\mathrm{S} / \mathrm{E}$ \\
\hline 8 & Erythromelalgia & 8 & 4 & 0.075 & 0.15 & 4 & None & $\mathrm{y}$ & . \\
\hline 9 & PLPS-L & 8 & 4 & 0.15 & 0.15 & 3 & I & $\mathrm{n}$ & Cost \\
\hline 10 & PLPS-L & 8 & 4 & 0.15 & 0.5 & 3 & I & $\mathrm{y}$ & . \\
\hline 11 & PLPS-L & 6 & 5 & 0.15 & 0.3 & 2 & DU & $\mathrm{n}$ & S/E \\
\hline 12 & PLPS-L & 7 & 3 & 0.15 & 0.15 & 5 & DU & $\mathrm{n}$ & $\mathrm{S} / \mathrm{E}$ \\
\hline 13 & PLPS-L & 7 & 2 & 0.3 & 0.7 & 4 & None & $\mathrm{y}$ & . \\
\hline 14 & PLPS-C & 7 & 3 & 0.3 & 0.5 & 3 & $\mathrm{~N}$ & $\mathrm{n}$ & Cost \\
\hline 15 & PLPS-C & 8 & 7 & 0.075 & 0.075 & 2 & N/V, I & $\mathrm{n}$ & $\mathrm{NE}, \mathrm{S} / \mathrm{E}$ \\
\hline 16 & PLPS-C & 4 & 3 & 0.15 & 0.15 & 1 & DU, I & $\mathrm{n}$ & $\mathrm{S} / \mathrm{E}$ \\
\hline 17 & MPS & 9 & 9 & 0.3 & 0.5 & 2 & I, PDPH & $\mathrm{n}$ & $\mathrm{NE}$ \\
\hline 18 & Functional abdominal pain & 9 & 8 & 0.15 & 0.15 & 3 & $\mathrm{~N}, \mathrm{D}, \mathrm{I}$ & $\mathrm{n}$ & $\mathrm{NE}, \mathrm{S} / \mathrm{E}$ \\
\hline 19 & Peripheral neuropathy & 6 & 2 & 0.075 & 0.15 & 3 & DU & $\mathrm{n}$ & Cost \\
\hline 20 & PHN & 7 & 7 & 0.15 & 0.5 & 3 & None & $\mathrm{n}$ & NE \\
\hline
\end{tabular}

S: starting dose, F: final dose, No: number of test, DU: dysuria, I: itching, N: nausea, V: vomiting, D: dizziness, S/E: side effect, NE: no effect, y: yes, n: no. 


\section{Discussion}

IT use of opioids has been growing with the development of the implantable ITDP for either malignant or non-malignant chronic pain, since opioid receptors in the nervous system were found in the late 1970s [6,7]. In Korea, the implantable ITDP was introduced in 2007, and a gradually increasing number of implantable ITDPs has been used to manage intractable chronic pain [8].

In clinical practice, there are many causes of prolonged pain, as, for example, PLPS, CRPS, central pain, axial spinal pain with a non-specific origin, peripheral neuropathy, peripheral and central neuropathic pain caused by brachial plexitis, spinal cord injury etc., and failed spinal cord stimulation (SCS) therapy. In this study, the most common cause of chronic pain was PLPS, followed by CRPS. Although this study did not involve a randomized controlled trial, CRPS and PLPS patients had considerably good responses to IT morphine infusion; 75\% (3/4) of the CRPS patients and $63 \%$ (5/8) of the PLPS patients had positive responses, among whom two of the four CRPS patients and two of the eight PLPS patients chose implantation of an ITDP.

Most clinical practitioners' concerns about ITDP using morphine must be how much morphine would best relieve pain without side effects. It is important to estimate the side effects of IT morphine before deciding to perform the ITDP implantation. There is no standard method, however, of determining the proper dose of IT morphine before implantation of ITDP with morphine. So far, trial IT morphine injection has been performed either via intrathecal or epidural bolus injection or via continuous inthrathecal or epidural infusion of an indwelling catheter. Unfortunately, four types of trial administration of morphine have a strong limitation as to their inability to prognosticate the long-term outcome. About 59.8\% of trial IT injections have been performed through the epidural route, but epidural medication could not estimate the direct IT drug effect, even though it does not need dural puncture [7].

Although trial injection through the IT route could more likely develop meningitis or PDPH via penetration of the dura, it is more likely to produce a side effect similar to that of morphine released from a real ITDP [9]. In this study, a 25-gauge $10 \mathrm{~cm}$ spinal needle (Hakko ${ }^{\circledR}$, Hakko, Japan) was used, and one patient who had PDPH was not clinically affected and his condition was resolved spontaneously without any treatment. Using an IT-indwelling catheter for continuous infusion would have conditions most similar to those of ITDP infusion, but infection and CSF leakage could be causes for greater concern. Furthermore, there is currently no commercial IT-indwelling catheter in Korea. In this study, the patients underwent daily sequential IT single-shot injections to access a direct subarachnoid space for administration of the drug and to adjust the dose of morphine more properly. Generally, morphine has water-soluble pharmacokinetics, and the onset of its action occurs in approximately 30 minutes to 1 hour, with an effect that lasts as long as $18-24$ hours [10]. The treatment goal in this study was at least $50 \%$ pain relief, which was the end point of the trial IT injection. Furthermore, in this study, the same amount of normal saline was injected intrathecally if the patient reported a positive response, which excluded the placebo effect.

In conclusion, the results of this study show that daily sequential IT morphine injection combined with placebo injection as a trial ITDP would be useful in evaluating the effectiveness and adverse effects of IT morphine infusion without clinically significant complications. In addition, daily incremental doses of $0.2 \mathrm{mg}$ of morphine could be an easy and safe way to determine the appropriate dose of morphine for the initiation of the ITDP implantation.

\section{References}

1. Breivik H, Collett B, Ventafridda V, Cohen R, Gallacher D. Survey of chronic pain in Europe: prevalence, impact on daily life, and treatment. Eur J Pain 2006; 10: 287-333.

2. Hosobuchi Y, Adams JE, Rutkin B. Chronic thalamic stimulation for the control of facial anesthesia dolorosa. Arch Neurol 1973; 29: 15861 .

3. Kumar A, Felderhof C, Eljamel MS. Spinal cord stimulation for the treatment of refractory unilateral limb pain syndromes. Stereotact Funct Neurosurg 2003; 81: 70-4.

4. Pert CB, Snyder SH. Opiate receptor: demonstration in nervous tissue. Science 1973; 179: 1011-4.

5. Wang JK, Nauss LA, Thomas JE. Pain relief by intrathecally applied morphine in man. Anesthesiology 1979; 50: 149-51.

6. Onofrio BM, Yaksh TL, Arnold PG. Continuous low-dose intrathecal morphine administration in the treatment of chronic pain of malignant origin. Mayo Clin Proc 1981; 56: 516-20.

7. Paice JA, Penn RD, Shott S. Intraspinal morphine for chronic pain: a retrospective, multicenter study. J Pain Symptom Manage 1996; 11: 71-80.

8. Seo KS, Han KR, Kim SY, Park KE, Kim C. Implantable intrathecal drug delivery pump in complex regional pain syndrome patient: a case report. Korean J Pain 2009; 22: 74-7.

9. Burke D, Wildsmith JA. Meningitis after spinal anaesthesia. Br J Anaesth 1997; 78: 635-6.

10. France JC, Jorgenson SS, Lowe TG, Dwyer AP. The use of intrathecal morphine for analgesia after posterolateral lumbar fusion: a prospective, double-blind, randomized study. Spine (Phila Pa 1976) 1997; 22: 2272-7. 